\title{
The RNA-Binding Protein SBR (Dm NXF1) Is Required for the Constitution of Medulla Boundaries in Drosophila melanogaster Optic Lobes
}

\author{
Ludmila Mamon ${ }^{1}$, Anna Yakimova ${ }^{2}$, Daria Kopytova ${ }^{3}$ (1) and Elena Golubkova ${ }^{1, *}$ \\ 1 Department of Genetics and Biotechnology, Saint-Petersburg State University, Universitetskaya Emb. 7/9, \\ 199034 St. Petersburg, Russia; mamon@LM2010.spb.edu or 1.mamon@spbu.ru \\ 2 A. Tsyb Medical Radiological Research Center-Branch of the National Medical Research Radiological Center \\ of the Ministry of Health of the Russian Federation, Koroleva Str. 4, 249036 Obninsk, Russia; \\ anna.prosovskaya@gmail.com \\ 3 Institute of Gene Biology, Russian Academy of Sciences, Vavilov St. 34/5, 119334 Moscow, Russia; \\ dvkopytova@gmail.com \\ * Correspondence: e.golubkova@spbu.ru or elena_golubkova@mail.ru
}

Citation: Mamon, L.; Yakimova, A.; Kopytova, D.; Golubkova, E. The RNA-Binding Protein SBR (Dm NXF1) Is Required for the Constitution of Medulla Boundaries in Drosophila melanogaster Optic Lobes. Cells 2021, 10, 1144. https://doi.org/ 10.3390/cells10051144

Academic Editor: Krzysztof Jagla

Received: 18 April 2021

Accepted: 6 May 2021

Published: 10 May 2021

Publisher's Note: MDPI stays neutral with regard to jurisdictional claims in published maps and institutional affiliations.

Copyright: (c) 2021 by the authors. Licensee MDPI, Basel, Switzerland. This article is an open access article distributed under the terms and conditions of the Creative Commons Attribution (CC BY) license (https:/ / creativecommons.org/licenses/by/ $4.0 /)$.

\begin{abstract}
Drosophila melanogaster sbr (small bristles) is an orthologue of the Nxf1 (nuclear export factor 1) genes in different Opisthokonta. The known function of Nxf1 genes is the export of various mRNAs from the nucleus to the cytoplasm. The cytoplasmic localization of the SBR protein indicates that the nuclear export function is not the only function of this gene in Drosophila. RNA-binding protein SBR enriches the nucleus and cytoplasm of specific neurons and glial cells. In $s b r^{12}$ mutant males, the disturbance of medulla boundaries correlates with the defects of photoreceptor axons pathfinding, axon bundle individualization, and developmental neurodegeneration. RNA-binding protein SBR participates in processes allowing axons to reach and identify their targets.
\end{abstract}

Keywords: neurogenesis; optic lobe; Drosophila; NXF; RNA-binding protein

\section{Introduction}

Drosophila melanogaster sbr (small bristles) is an orthologue of the Nxf1 (nuclear export factor 1) genes in different organisms, including human [1-3]. The best known function of the Nxf1 genes is the transport of various mRNAs from the nucleus to the cytoplasm [1]. NXF1 is localized in the nucleus or the nuclear envelope according to its function [4]. As we have shown previously, D. melanogaster SBR (Dm NXF1) is located not only in the nucleus but also in the cytoplasm of different cells [5-7]. This finding suggests that the SBR protein has specific cytoplasmic functions in addition to its participation in nuclear export of mRNAs. In the Drosophila larval brain, SBR forms granules in the neuron bodies and neurites [7]. Some granules contain two RNA-binding proteins, SBR and dFMR1 (drosophila Fragile Mental Retardation 1), which are known components of RNP-granules. Others are marked by either FMR1 or SBR. These observations suggest that SBR has specific localized RNA targets in the cytoplasm [8]. Regulated translation of localized mRNAs is a widespread and essential process during neurogenesis [9].

Neurogenesis in Drosophila is a highly organized process that requires strict regulation of the compartments individualization and the establishment of the correct connections between neurons. Intercellular communications are an important mediator of axon guidance, proper axon bundle track, and neuron survival [10-12]. Together with RNA binding proteins, localized RNAs in complex create a system of rapid and long-term production of signal or receptor molecules near cellular membranes of glial cells, neurons and their neurites. This determines intercellular communications and allows for the appropriate boundaries to be established between the compartments in the brain. The optic lobes of the fly brain are a model of neuropil compartmentalization, playing a 
crucial role in the development of the nervous system. Each of the optic lobes is divided into four brain compartments (neuropils): lamina, medulla, lobula, and lobula plate [13]. The compound eyes of D. melanogaster consist of single units called ommatidia. Each ommatidium contains eight photoreceptor neurons (R1-R8) that project into the optic lobe of the brain following the neural superposition rule [14,15]. This rule ensures that the axons from the retina cells obtain information from the same point in space projected onto the same cartridge of the lamina or column of the medulla. The axons of the photoreceptor neurons R1-R6 form the lamina plexus in a retinotopic manner, subdividing the lamina neuropil into synaptic cartridges. Each cartridge contains terminals of the R1-R6 photoreceptor neurons located in the neighboring ommatidia and detect the same visual point of space [16]. The axons of the R7-R8 photoreceptor neurons cross the lamina and terminate in the medulla (Figure 1) $[17,18]$.

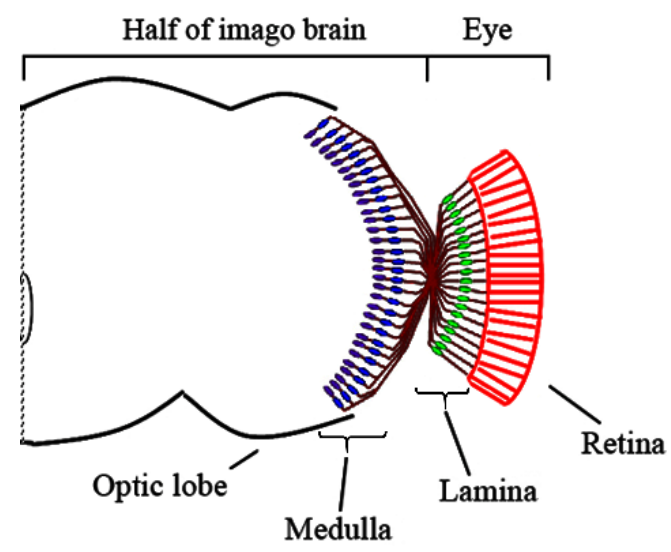

Figure 1. Location of the axon terminals of the R1-R8 photoreceptor neurons in an optic lobe of the imago brain. The R1-R6 axons terminate in the lamina (depicted in green), and the R8 (blue) and R7 (violet) axons terminate in the medulla (from [18] with changes).

Morphological defects in the optic lobes and ellipsoid body are the dominant features of $s b r^{12}$ mutant males, characterized by low activity in the negative geotaxis test [19]. We discuss the role of the $s b r(D m n x f 1)$ gene in establishing medulla compartment boundaries in Drosophila melanogaster optic lobes. The defects of the photoreceptor axons pathfinding, axon bundle individualization, and developmental neurodegeneration are essential for the formation of medulla boundaries in $s b r^{12}$ mutant males. Non-random cytoplasmic localization of RNA-binding protein SBR suggests it plays a role in the processes allowing axons to reach and identify their targets.

\section{Materials and Methods}

\subsection{Strains and Hybrids}

The vitally important $D$. melanogaster gene $s b r(D m n x f 1)$ is located on the $\mathrm{X}$ chromosome, whereas the orthologous nxf1 genes of vertebrates are located on autosomal chromosomes. Since homozygous or hemizygous carriage of the $s b r^{12}$ allele is lethal, viable male carriers of $s b r^{12}$ can be obtained by crossing $s b r^{12} / F M 6$ females with males that carry $s b r^{+}$as a part of the $D p(1 ; Y) y^{+} v^{+}$duplication on the $\mathrm{Y}$ chromosome. $s b r^{12} / D p(1 ; Y) y^{+} v^{+}$ males differ from wild type males not only in the presence of the mutant $s b r^{12}$ allele, they also have two copies of the $s b r$ gene. In $s b r^{12} / D p(1 ; Y) y^{+} v^{+}$males, the extra $s b r^{+}$allele lies on the $Y$ chromosome. This fact is especially important for genes normally localized on the $\mathrm{X}$ chromosome. The transcriptional level of $\mathrm{X}$ chromosome-linked genes is regulated by the dosage compensation mechanism [20]. Therefore, additional control variants are required to study $s b r^{12}$ phenotypes. $L 4 / D p(1 ; Y) y^{+} v^{+}$males with a deletion of the $s b r$ gene on the $\mathrm{X}$ chromosome $\left(D f(1) v-L 4, r a s^{2} m^{D}\right)$ and an $s b r^{+}$allele on the $\mathrm{Y}$ chromosome provide an opportunity to explore the impacts of one copy of the $s b r^{+}$allele due to its unusual localization. 
Another additional control is $s b r^{+} / D p(1 ; Y) y^{+} v^{+}$males, which have a double dose of $s b r^{+}$(one on the $\mathrm{X}$ chromosome and another on the $\mathrm{Y}$ chromosome). This control equalizes $s b r^{12} / D p(1 ; Y) y^{+} v^{+}$animals to $s b r^{+} / D p(1 ; Y) y^{+} v^{+}$animals in relation to the $s b r$ gene dose. The additional controls help to differentiate the phenotypes of the $s b r^{12}$ allele from those of the double dose of the $s b r$ gene and the unusual chromosomal localization of the $s b r^{+}$allele.

Heterozygous males $s b r^{12} / D p(1 ; Y)$ have full-size SBR protein along with the SBR ${ }^{12}$ protein that carried deletion of 10 a.a. (TIFITNATHE) at the C-terminal part of the protein. The $s b r^{12}$ allele has the dominant-negative effect on male fertility, locomotion activity, and the brain abnormality, what is characterizing the gain of function alleles. We considered the possibility of other mutations in the same X-chromosome and used recombination mapping for finding an additional mutant allele. Results are presented in Appendix A.

\subsection{Sample Collection}

Third instar male larvae were used to analyze the structure of the medulla in the developing brain, as well as to study the location of the photoreceptor neurons in the eye-antennal imaginal discs (EAIDs). EAIDs were dissected in a cold PBS solution. In this case, brains with intact EAIDs were dissected for immunohistochemical staining (see below for details).

The heads of 3-5-day-old adult males were dissected in cold PBS to examine the brain structure and the location of the photoreceptor neuron terminals in the medulla using fluorescent staining (see below for details). All brain centers are already formed at this age [21]. Paraffin sections of the imago head were stained with haematoxylin and eosin to analyze the optic lobe structure.

\subsection{Immunohistochemical and Fluorescent Staining}

Fixation of dissected larval and imaginal brains was performed in $4 \%$ formaldehyde in PBS for $15 \mathrm{~min}$ at room temperature. Each brain was washed 3 times for 15 min each in PBST (PBS supplemented with 0.1\% Tween-20). Permeabilization was performed in PBS with $0.3 \%$ Tween-20 for $30 \mathrm{~min}$ at room temperature. Subsequently, the brains were incubated for $2 \mathrm{~h}$ in blocking solution (10\% fetal calf serum (FCS) in PBST) at $4{ }^{\circ} \mathrm{C}$ to avoid non-specific antibody binding. Antibodies to horseradish peroxidase (HRP), conjugated with GFP (Jackson ImmunoResearch Laboratories, West Baltimore Pike, PA, USA, 1:250 in blocking solution, overnight at $+4^{\circ} \mathrm{C}$ ) were used to identify the neuropils, the photoreceptor neurons, and their processes in the EAID and larval brain [22]. Rabbit polyclonal antibodies to SBR [23] were used for the visualization of SBR protein in Drosophila brain and EAID (1:100 in blocking solution, overnight at $+4^{\circ} \mathrm{C}$ ). Mouse monoclonal antibodies to Chaoptin (24b10, Developmental Studies Hybridoma Bank, Iowa City, IA, USA) were used for the visualization of photoreceptor neurons and their processes in the imago brain (1:50 in blocking solution, overnight at $+4{ }^{\circ} \mathrm{C}$ ). Subsequently, each brain was washed 4 times for 15 min each in PBST and were stained with the secondary goat anti-rabbit antibodies, conjugated with AlexaFluor-647 (1:1000 in blocking solution, overnight at $\left.+4{ }^{\circ} \mathrm{C}\right)$ and /or secondary goat anti-mouse antibodies, conjugated with AlexaFluor-555 (1:1000 in blocking solution, overnight at $+4^{\circ} \mathrm{C}$ ). Subsequently, each brain was washed 4 times for $15 \mathrm{~min}$ each in PBST and 2 times for 15 min each in PBS. Nuclei were stained with DAPI $(1 \mu \mathrm{g} / \mathrm{mL}$ in PBS) for $15 \mathrm{~min}$ at room temperature. Each brain was then washed 3 times for $10 \mathrm{~min}$ each in PBS and mounted in Vectashield Mounting Medium (Vector Laboratories, Burlingame, CA, USA).

\subsection{Head Paraffin Sections}

Flies were fixed in $4 \%$ formaldehyde in PBS overnight at $+4{ }^{\circ} \mathrm{C}$. Dehydration and paraffinization was carried out using the standard method [24]. Serial head sections with a thickness of $5 \mu \mathrm{m}$ were obtained using a microtome and transferred to glass slides coated with poly-L-lysine. Subsequently, the sections were deparaffinized, hydrated, and stained 
with haematoxylin-eosin using the standard method [24]. After that, the sections were dehydrated, incubated in xylene (2 times for $3 \mathrm{~min}$ ), and mounted in Canadian Balsam.

\subsection{Microscopy}

The analysis of the preparations was carried out using a Leica TCS SP5 laser scanning confocal microscope (Leica Microsystems GmbH, Wetzlar, Germany) at the Chromas Center for Collective Use at the St. Petersburg State University and a Leica DMI4000 laser scanning confocal microscope based in the Radiation Biochemistry Laboratory of the A. Tsyb Medical Radiological Research Center, a branch of the National Medical Research Radiological Center of the Ministry of Health of the Russian Federation (A. Tsyb MRRC), Obninsk, Russia.

To visualize of the photoreceptors in the imago brain, autofluorescence was detected by means of excitation with a $488 \mathrm{~nm}$ exciting laser and a $530-580 \mathrm{~nm}$ blocking filter. With these scanning parameters, the autofluorescence of the photoreceptors with their axons is clearly observable, despite the presence of background autofluorescence from other tissues of D. melanogaster.

To visualize the internal structure of the lamina and medulla in the imago brain, autofluorescence of stained head paraffin sections was detected a laser with an excitation peak at $488 \mathrm{~nm}$ exciting laser and a 530-600 $\mathrm{nm}$ blocking filter. This approach made it possible to precisely focus on the surface of the paraffin section and to get a highresolution image.

Fluorescence of anti-IgG::AlexaFluor-647, anti-HRP::GFP, and DAPI were detected following the manufacture's manual.

The obtained images were processed using computer image analysis systems, such as LAS AF Lite.

V1.7.0 (Leica Microsystems GmbH, Wetzlar, Germany) and ImageJ, as well as Adobe Photoshop V7.0 (Adobe Systems Incorporated, San Jose, CA, USA) were utilized to arrange composite images and drawing explanatory marks (arrows, contours) to simplify the visualization of the results.

\section{Results}

\subsection{Medulla Malformations in $\operatorname{sbr} r^{12} / D p(1 ; Y) y^{+} v^{+}$Males}

The medulla neuropil is a highly ordered structure consisting of multiple synaptic layers. Projections of the R7-R8 photoreceptors terminate in different medullar layers (M3 and M6, respectively) and form strictly ordered synaptic connections with projections of the lamina and medulla neurons. Medulla columns are oriented perpendicular to the ten synaptic medulla layers [25].

In Oregon- $R, s b r^{+} / D p(1 ; Y) y^{+} v^{+}$and $L 4 / D p(1 ; Y) y^{+} v^{+}$adult males, the medulla has clear smooth boundaries (Figure 2a,b,d). Only in $s b r^{12} / D p(1 ; Y) y^{+} v^{+}$males, the medulla appears to have lost its integrity (Figure 2c). External boundary of the medulla in $s b r^{12} / D p(1 ; Y) y^{+} v^{+}$ males looks like separate protrusions and hollows in all cases with variation of malformation degree. It is a dominant negative effect of the $\mathrm{SBR}^{12}$ protein rather than a consequence of the decrease in the content of the SBR protein, since similar disorders are absent in males $L 4 / D p(1 ; Y) y^{+} v^{+}$with the $s b r$ gene deletion $\left(L 4-D f(1) v-L 4, r a s^{2} m^{D}\right)$ (Figure $2 \mathrm{~d}$ ).

The structure of the medulla columns was visualized by autofluorescence of adult Drosophila brain on the paraffin sections (Figure $3 \mathrm{a}, \mathrm{b}$ ). In wild type Oregon- $R$ males, organization of the medulla columns is ordered (Figure 3a'). A striking feature of $s b r^{12} / D p(1 ; Y) y^{+} v^{+}$ males is that the medulla columns are disorganized and non-structured (Figure $3 b^{\prime}$ ). 


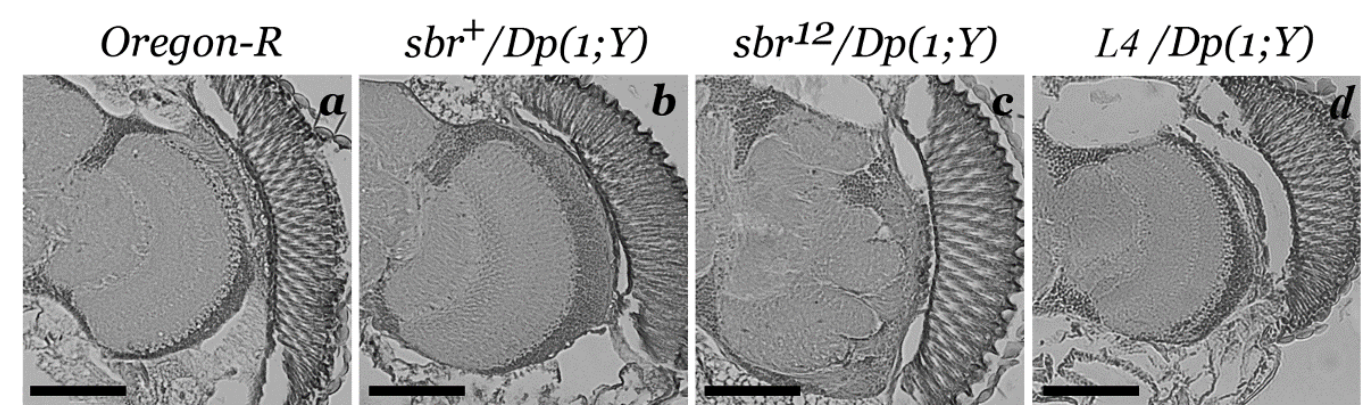

Figure 2. Paraffin sections of the optic lobes from the heads of males of different genotypes ((a)-Oregon-R, (b)$s b r^{+} / D p(1 ; Y) y^{+} v^{+},(\mathbf{c})-s b r^{12} / D p(1 ; Y) y^{+} v^{+}$and $\left.(\mathbf{d})-D f(1) v-L 4, \operatorname{ras}^{2} m^{D} / D p(1 ; Y) y^{+} v^{+}\right)$. Haematoxylin and eosin staining. The section at the level of the medulla is in the front third of the brain. Scale bar: $75 \mu \mathrm{m}$.

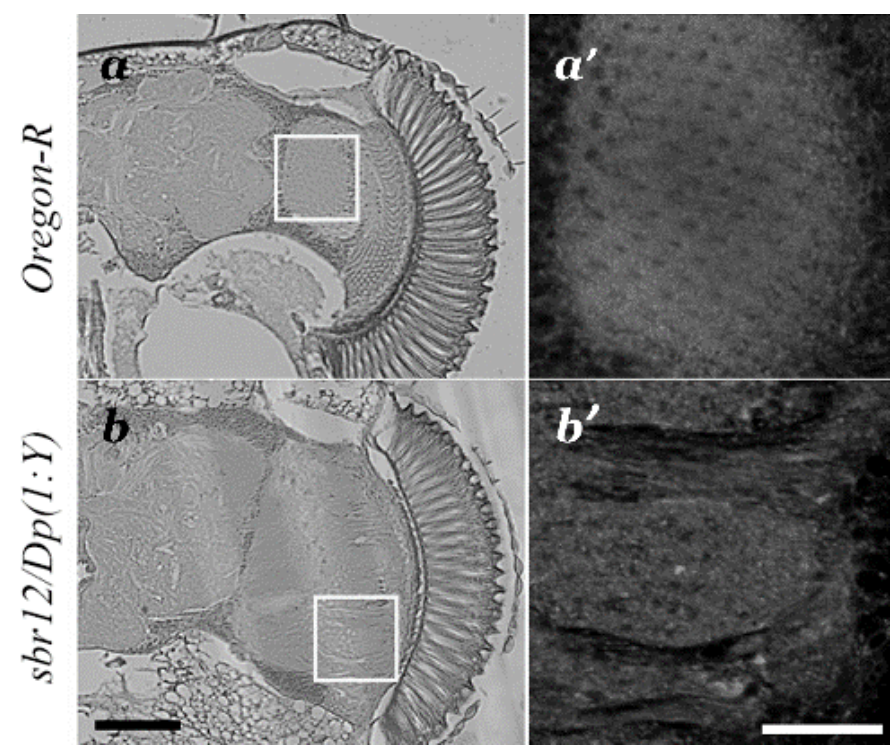

Figure 3. Paraffin sections of the adult Drosophila brain of Oregon-R $\left(\mathbf{a}, \mathbf{a}^{\prime}\right)$ and $s b r^{12} / D p(1 ; Y) y^{+} v^{+}$ $\left(\mathbf{b}, \mathbf{b}^{\prime}\right)$ males. Architecture of medulla columns $\left(\mathbf{a}^{\prime}, \mathbf{b}^{\prime}\right)$ are visualized by autofluorescence in the regions marked on the images $(\mathbf{a}, \mathbf{b})$. Medulla columns are ordered in Oregon- $R$ males $\left(\mathbf{a}^{\prime}\right)$ and are disorganized in $\operatorname{sbr}^{12} / D p(1 ; Y) y^{+} v^{+}$males $\left(\mathbf{b}^{\prime}\right)$. Scale bar: $(\mathbf{a}, \mathbf{b})-75 \mu \mathrm{m} ;\left(\mathbf{a}^{\prime}, \mathbf{b}^{\prime}\right)-25 \mu \mathrm{m}$.

The pattern of the structural disorganization of the medulla suggests that this disorganization could be caused by pathfinding defects in the photoreceptor axons. If that indeed were the case, then the axons of the photoreceptor neurons would not reach their targets and would not establish the correct connectome. To test this hypothesis, we investigated the locations of the photoreceptor terminals in the medulla of the whole adult Drosophila brain via confocal microscopy with the use of the antibody (Figure 4) and analysis of autofluorescence (Figure S1). The anti-chaoptin immunolabeling allows to visualize the terminal locations of the photoreceptors. The detection of the chaoptin demonstrated that the photoreceptor terminals were arranged in order, forming rows in the distal part of the medulla in the wild type (Figure $\left.4 \mathrm{a}^{\prime}, \mathrm{a}^{\prime \prime}\right), s b r^{+} / D p(1 ; Y) y^{+} v^{+}$(Figure $\left.4 \mathrm{~b}^{\prime}, \mathrm{b}^{\prime \prime}\right)$, and $L 4 / D p(1 ; Y) y^{+} v^{+}$males (Figure $\left.4 \mathrm{~d}^{\prime}, \mathrm{d}^{\prime \prime}\right)$. In $s b r^{12} / D p(1 ; Y) y^{+} v^{+}$males, the photoreceptor terminals were located chaotically and did not form ordered rows (Figure $\left.4 c^{\prime}, c^{\prime \prime}\right)$. 


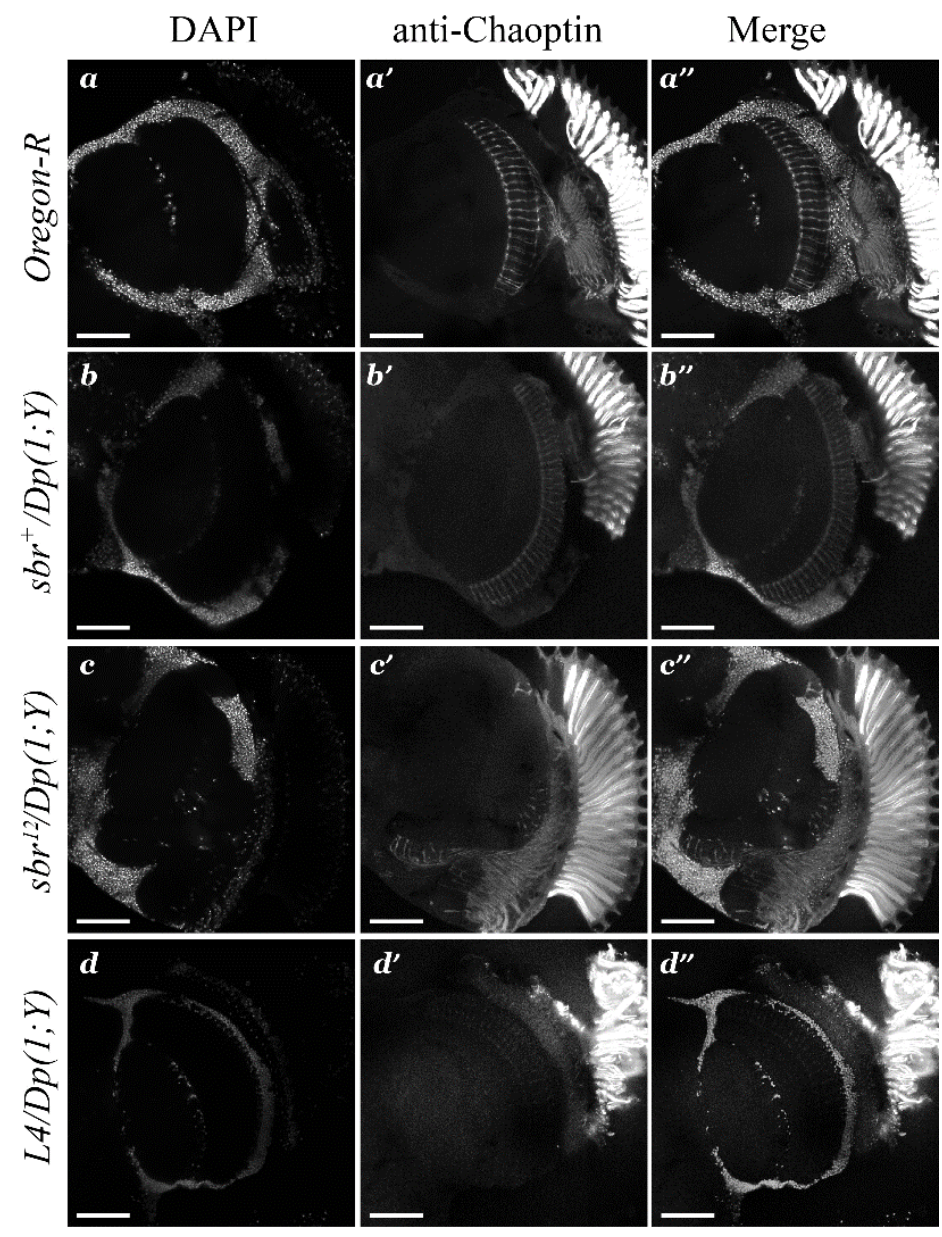

Figure 4. Axon terminals of the photoreceptors in the medulla of the optic lobe in adult males of different genotypes $\left(\mathbf{a}, \mathbf{a}^{\prime}, \mathbf{a}^{\prime \prime}\right.$-Oregon-R; $\mathbf{b}, \mathbf{b}^{\prime}, \mathbf{b}^{\prime \prime}-s b r^{+} / D p(1 ; Y) y^{+} v^{+} ; \mathbf{c}, \mathbf{c}^{\prime}, \mathbf{c}^{\prime \prime}-s b r^{12} / D p(1 ; Y) y^{+} v^{+} ; \mathbf{d}, \mathbf{d}^{\prime}, \mathbf{d}^{\prime \prime}-$ $\left.D f(1) v-L 4, \operatorname{ras}^{2} m^{D} / D p(1 ; Y) y^{+} v^{+}\right)$. Cell nuclei were stained with DAPI (a-d). Antibodies to Chaoptin allows to detect photoreceptor axon terminals $\left(\mathbf{a}^{\prime}-\mathbf{d}^{\prime}\right.$ and $\mathbf{a}^{\prime \prime}-\mathbf{d}^{\prime \prime}-$ merge). In $s b r^{12} / D p(1 ; Y) y^{+} v^{+}$axon terminals are not ordered and the medulla structure is disrupted $\left(\mathbf{c}^{\prime}, \mathbf{c}^{\prime \prime}\right)$. Scale bar: $50 \mu \mathrm{m}$.

The R7 and R8 neurons are the pioneer neurons during the organization of the medullar layers. The axons of these photoreceptors grow first to the medulla and then serve as a navigational guide for the axons of other neurons, which participate in the formation of the individual columns [26]. Therefore, the breach of the boundary between the lamina and the medulla in $s b r^{12} / D p(1 ; Y) y^{+} v^{+}$males suggests that the process of coordinated termination of photoreceptor neurons is defective (Figure $4 c^{\prime}, c^{\prime \prime}$ ). These types of disruptions may indicate both problems with pathfinding of the axons of photoreceptor neurons to their targets, and with the specification of photoreceptor neurons. To shed light on the reasons for the observed defects, we investigated the formation of the photoreceptor axons at earlier developmental stages.

\subsection{Defects in Fasciculation of Photoreceptor Axons in Eye-Antennal Imaginal Discs of $s b r^{12} / D p(1 ; Y) y^{+} v^{+}$Male Larvae}

Antibodies to the plant glycoprotein horseradish peroxidase (HRP) recognize the fly neuronal membrane [22] and allow for the identification of photoreceptors with their neurites. In the eye part of the eye-antennal imaginal discs (EAIDs) of the Drosophila third instar larvae, the projections of photoreceptors belonging to different ommatidia interact with each other via cell adhesion proteins. They form axonal tracts that then further consolidate into the optic nerves that connect each EAID to the respective optic lobe of the developing brain. 
Only $s b r^{12} / D p(1 ; Y) y^{+} v^{+}$males have a defective fasciculation (bundling) of the axons of the photoreceptor neurons in the EAIDs (Figure 5C). The axon bundles were located chaotically (Figure 5C,F) and not in parallel rows as observed in males of control genotypes (Figure 5A,B,D,E).

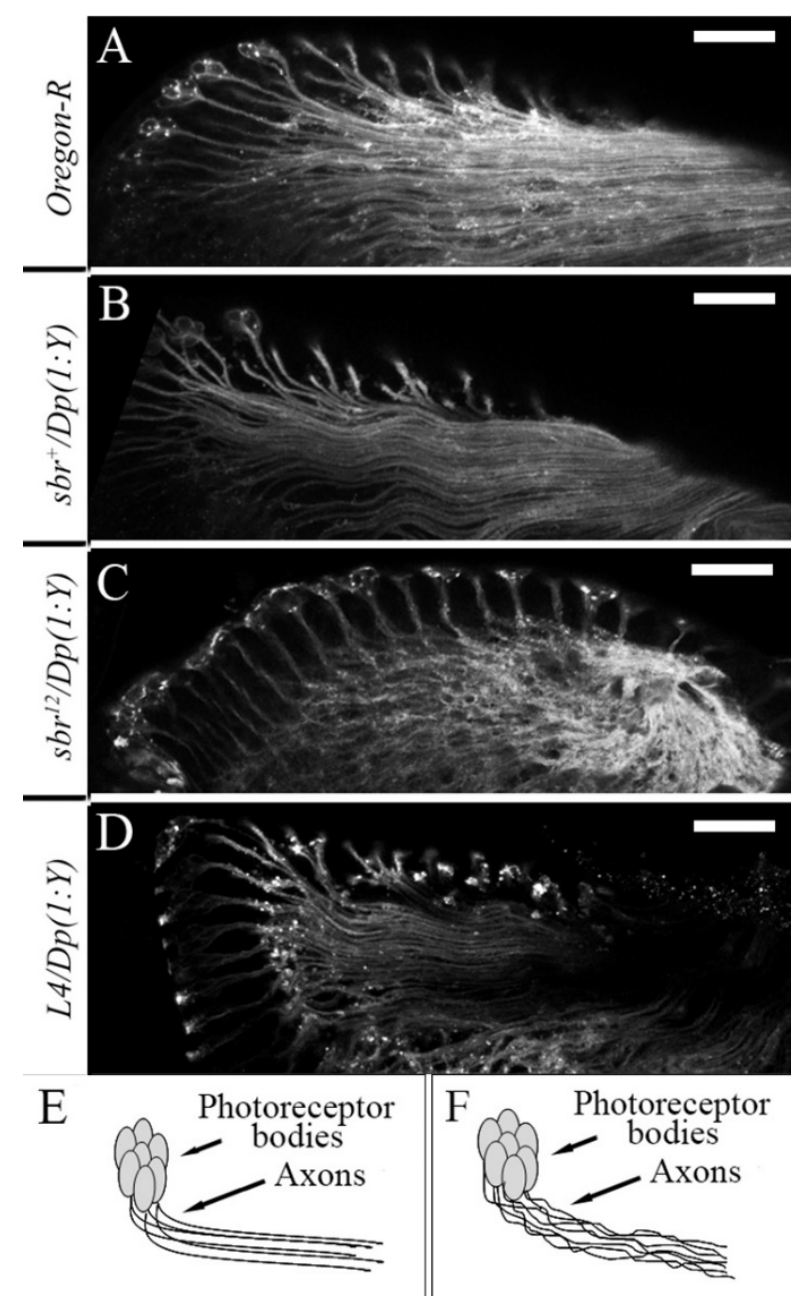

Figure 5. Localization patterns of the photoreceptor axons in the EAIDs of third instar male larvae. The photoreceptors and their axons were labelled with antibodies against HRP. (A-D)—maximal projections of the optic section series through the EAID zone, which contains photoreceptors and their axons, in males with the following genotypes: (A) -Oregon- $R,(\mathbf{B})-s b r^{+} / D p(1 ; Y) y^{+} v^{+},(\mathbf{C})-$ $s b r^{12} / D p(1 ; Y) y^{+} v^{+}$, and (D) - Df(1)v-L4, $\operatorname{ras}^{2} m^{D} / D p(1 ; Y) y^{+} v^{+}$. Schematic images of photoreceptor axon localization: (E)—Oregon-R, (F)—sbr $12 / D p(1 ; Y) y^{+} v^{+}$. In $s b r^{12} / D p(1 ; Y) y^{+} v^{+}$males, the axon bundles are weak ordered and do not form parallel rows $(\mathbf{C}, \mathbf{E})$; the photoreceptor axons are parallel to each other in males of control genotypes (A,B,D,E). Scale bar: $20 \mu \mathrm{m}$.

This is consistent with disorganized structure of the medullar columns in $s b r^{12} / D p(1 ; Y) y^{+} v^{+}$ males (Figure $\left.3 b^{\prime}\right)$. The defects in the structure of the photoreceptor axons observed in the EAIDs of $s b r^{12} / D p(1 ; Y) y^{+} v^{+}$males suggested that the $s b r^{12}$ allele affects axon bundle organization. The axons of the photoreceptor neurons form the optic nerve passing from the EAIDs to the brain. The most impressive phenotype of the $s b r^{12}$ allele is the disturbance of medulla boundary and column architecture in the adult Drosophila brain (Figures $2 \mathrm{c}$ and $3 \mathrm{~b}^{\prime}$ ). These data suggest that the $s b r^{12}$ allele affects multiple processes, including axon growth, arborization, establishment of new cell-cell interactions, and the formation of the strictly ordered zone of the R axons. 


\subsection{Features of Neurodegeneration in the Medulla of $s b r^{12} / D p(1 ; Y) y^{+} v^{+}$Third Instar Male Larvae}

Staining with antibodies against HPR allows for the visualization of neuropils in the D. melanogaster larval brain. An analysis of the medulla structure in the developing optic lobes revealed that only $s b r^{12} / D p(1 ; Y) y^{+} v^{+}$males have features of neurodegeneration, including round black spots without any visual markers (Figure $\left.6 c^{\prime}\right)$. Moreover, $s b r^{12} / D p(1 ; Y) y^{+} v^{+}$males have a defective medulla shape and localization pattern of the neuron bodies in this zone of the brain. The medulla neuropil normally looks like a sickle during the third instar larvae. This zone was easily visualized with antibodies against HRP (Figure $6 a^{\prime}-d^{\prime}$ ), and the cell nuclei were distributed on the periphery of the medulla neuropil (Figure 6a-d). In $s b r^{12} / D p(1 ; Y) y^{+} v^{+}$males, the medulla had a rough edge and a disordered structure. This abnormal medulla structure suggests that neuropil morphogenesis is defective in $s b r^{12} / D p(1 ; Y) y^{+} v^{+}$males (Figure $\left.6 c, c^{\prime}\right)$. Males of control genotypes did not show signs of neurodegeneration in the medulla or defects in neuropil structure (Figure $6 a^{\prime}, b^{\prime}, \mathrm{d}^{\prime}$ ).

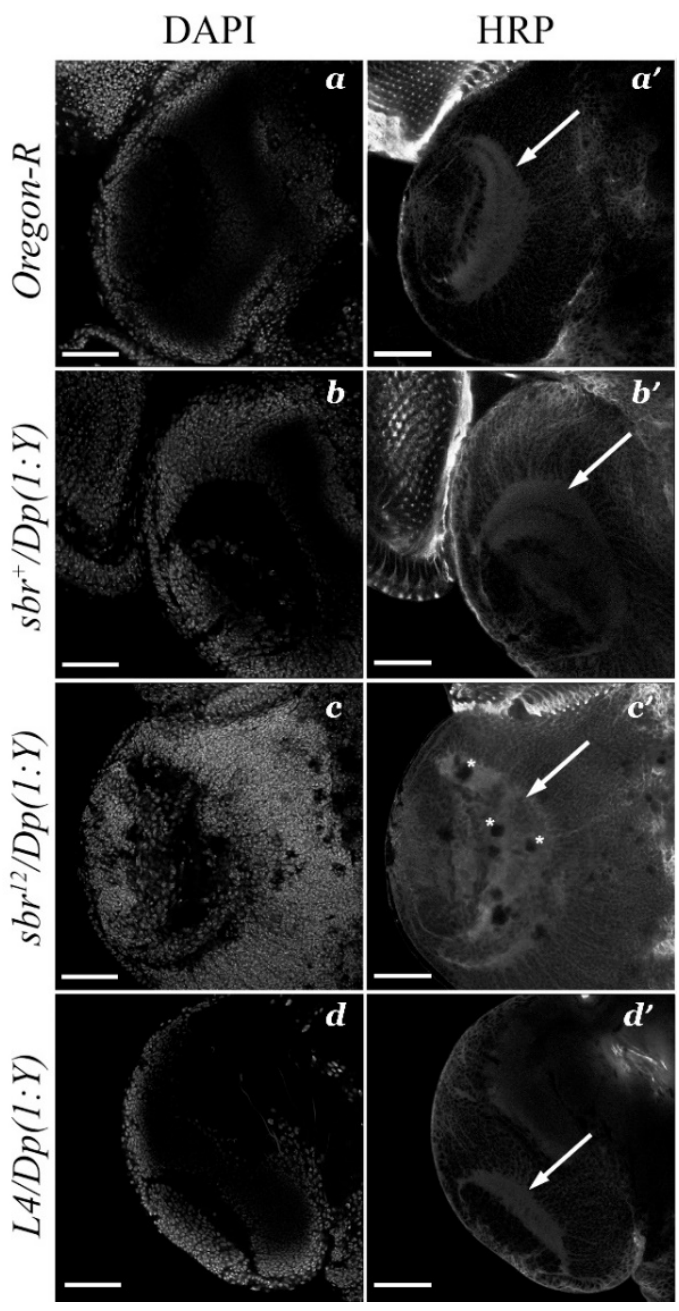

Figure 6. The medulla structure of third instar male larvae with different genotypes $\left(\mathbf{a}, \mathbf{a}^{\prime}-\right.$ Oregon- $R$, $\mathbf{b}, \mathbf{b}^{\prime}-s b r^{+} / D p(1 ; Y) y^{+} v^{+}, \mathbf{c}, \mathbf{c}^{\prime}-s b r^{12} / D p(1 ; Y) y^{+} v^{+}$and $\left.\mathbf{d}, \mathbf{d}^{\prime}-D f(1) v-L 4, r a s^{2} m^{D} / D p(1 ; Y) y^{+} v^{+}\right)$. Defects in the medulla (arrows) structure, disturbances in the nuclei localization pattern and manifestations of neurodegeneration (round zones with neither DAPI nor anti-HRP staining, with examples indicated by asterisks) were detected only in $s b r^{12} / D p(1 ; Y) y^{+} v^{+}$males $\left(\mathbf{c}^{\prime}\right)$. Cell nuclei were stained with DAPI $(\mathbf{a}-\mathbf{d})$, and the neuropil was visualized with antibodies against HRP $\left(\mathbf{a}^{\prime}-\mathbf{d}^{\prime}\right)$. Scale bar: $50 \mu \mathrm{m}$.

Neurodegeneration in a developing medulla of the $s b r^{12} / D p(1 ; Y) y^{+} v^{+}$males supports our assumption that the disruption of the structure of synaptic columns and cartridges 
in the medulla and lamina could be caused by defects in photoreceptor axons targeting, because mistargeted neurons and their axons are eliminate during brain development [27].

\subsection{Localization of SBR Protein in Different Brain Cells}

Distribution of SBR in the brain as a whole and in specific cells can help understand this gene's functions by studying the results of the immunofluorescence analysis. Antibodies to the N-terminal end (2-112 aa) of SBR [23] are used to detect the distribution of SBR in different cells. SBR enriches the nuclei and the cytoplasm of some cells: the glia and the axons of photoreceptor neurons in the optic stalk (Figure $7 \mathrm{a}, \mathrm{a}^{\prime}, \mathrm{a}^{\prime \prime}, \mathrm{c}$ ), and some of the stem cells, which are the largest cells in the brain, and their progenies (Figure $\left.7 b, b^{\prime}, b^{\prime \prime}\right)$. SBR is localized both in the nuclei and the cytoplasm of these cells.
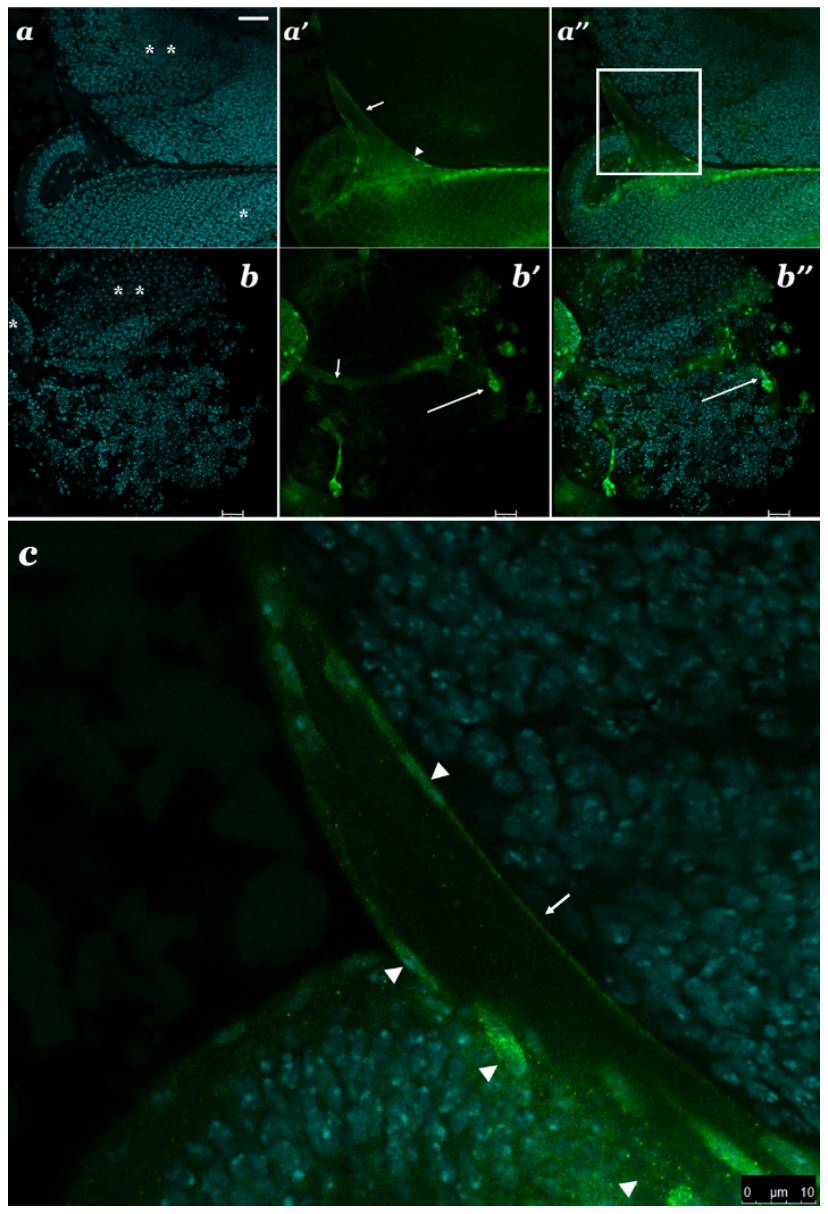

Figure 7. The optic section through optic stalk (arrow) connecting eye-antennal imaginal disc (EAID) ${ }^{(*)}$ with the brain $\left(^{* *}\right)$ of third instar larvae (Oregon-R). Localization of SBR in cells of the brain and/or EAID: DAPI for DNA in nuclei (blue) $(\mathbf{a}, \mathbf{b})$; anti-SBR antibody (green) $\left(\mathbf{a}^{\prime}, \mathbf{b}^{\prime}\right)$ and merge $\left(\mathbf{a}^{\prime \prime}, \mathbf{b}^{\prime \prime}\right)$; (c) - magnified image of the fragment from the $a^{\prime \prime}$ (framed). SBR enriches photoreceptor axons and the cytoplasm and some nuclei (arrow head) of proposed glial cells $\left(\mathbf{a}^{\prime}, \mathbf{a}^{\prime \prime}, \mathbf{c}\right)$. In EAID, the ommatidia boundaries is also detected by anti-SBR that looks like a green mesh $\left(\mathbf{a}^{\prime}\right)$. Anti-SBR allows to detect not only optic stalk (arrow) $\left(\mathbf{a}^{\prime}, \mathbf{b}^{\prime}\right)$, but also several neuroblasts (neuronal stem cells) (long arrow), and their daughter cells $\left(\mathbf{b}^{\prime}, \mathbf{b}^{\prime \prime}\right)$. SBR marks nuclei and the cytoplasm of these cognate cells. Scale bar: (a) $-25 \mu \mathrm{m},(\mathbf{b})-20 \mu \mathrm{m},(\mathbf{c})-10 \mu \mathrm{m}$.

Without special markers to glial cells it is not possible to detect cell specificity only by the morphological criteria alone. SBR enriches the cytoplasm and some nuclei of the glial cells ensheathing the optic stalk (Figure $7 \mathrm{a}^{\prime}, \mathrm{a}^{\prime \prime}, \mathrm{c}$ ). Glial functions are required for the proper development and survival of neurons, and a defective glia becomes the reason for multiple 
developmental abnormalities, including neuronal degeneration [12]. The glia plays an important role in establishing the boundaries between visual centers of the brain [28]. This could be an argument in favor of the participation of SBR participation in processes allowing axons to reach and identify their targets.

\section{Discussion}

4.1. The Assumed Cytoplasmic Functions of the SBR RNA-Binding Protein, an Orthologue of the Evolutionarily Conserved NXF1 Protein

The SBR (NXF1) protein participates in RNA nuclear transport. However, it has no specificity for different mRNA targets. The interactions between NXF1 and mRNAs do not occur directly, as special adapter molecules are required [1,29].

The $s b r^{12}$ allele carries a 30-nucleotide deletion in exon 9 [30]. The deletion of $30 \mathrm{bp}$ does not shift the reading frame in the coding part of the $s b r$ gene. In $\mathrm{SBR}^{12}$ protein, 10 amino acids (TIFITNATHE) are absent. As a result, the structure of the NTF2L domain is altered. The NTF2L domain is responsible for an interaction with the NXT1 (p15) protein, which is a permanent partner of NXF1 [4,31]. Moreover, the NTF2L domain (as well as the UBA domain) mediates the interaction between NXF1 and nucleoporins (the proteins of nuclear pore complexes) and subsequent transport of all RNP particles from the nucleus to the cytoplasm [31,32]. The structure of the NTF2L domain is important for interactions between NXF1 and various mRNAs and especially for its interaction with the intron-containing transcript of the $n x f 1$ gene, which was established in vertebrates $[33,34]$. It is unknown whether the analogous intron-containing transcript of the $s b r$ gene is a specific target for Drosophila SBR in the cytoplasm. The intron-containing transcript is more abundant among the sbr transcripts in the fly's head [35]. It is unknown whether the intron-containing transcript is the specific target of SBR in neurites.

The defects in the specific brain centers of $s b r^{12}$ male cannot be simply explained by a decrease in overall mRNA export. The $s b r^{12}$ allele has a dominant negative effect on the background of the normal $s b r^{+}$allele. We cannot exclude the possibility of selective effects of the $s b r^{12}$ allele on the nuclear transport of some mRNA targets. The presence of SBR ${ }^{12}$ may affect the export activity of specific mRNAs, which might include localized mRNAs important for neurogenesis. SBR is founded in ribonucleoprotein complexes in neurites, not all neuronal RNP granules are marked by the SBR protein. This observation suggests that SBR can also bind to its specific target RNAs in the cytoplasm [7].

Directed growth of the neurites allows them to reach their targets, and arborization and the establishment and maintenance of connections between neurons depend on dynamic changes in the cytoskeleton with regulated localized translation of localized mRNAs [36]. Non-random distribution of SBR in the cytoplasm of various cells, including nervous system cells [7], suggests that localized mRNAs associated with the cytoskeleton may be among the targets of SBR [8].

In the eye imaginal discs of $s b r^{12} / D p(1 ; Y) y^{+} v^{+}$males, the axons of the photoreceptors from the different ommatidia did not form strictly ordered bundles. This observation suggests a disruption in the connections between these axons and their terminals and targets. We cannot exclude the dominant-negative influence of the $s b r^{12}$ allele on the nuclear export of specific mRNAs. We have shown nonrandom cytoplasmic localization of the SBR proteins, which suggest additional cytoplasmic functions of the sbr gene. SBR is often localized near the cellular membrane (Figure S2). In the cytoplasm of various cells, SBR is found involved in granules (Figure 7c) [7], which are likely to be RNP-granules, since SBR is an RNA-binding protein. RNP-granules are quite complex and may contain proteins of signaling systems such as kinases and phosphatases [37]. This is required for the regulation of a localized mRNAs translation. The history of the discovery of TAP/Hs NXF1 (human ortholog of SBR) should be considered. TAP was first described as a cell adhesion factor (TAP-Tip Associated Protein, where tip-Tyrosine kinase Interacting Protein) [38]. Only later NXF1 (TAP) was identified as a protein involved in the nuclear export of different mRNAs [39]. 
Cell adhesion molecules play important roles not only in fasciculation but also in axon targeting, and their malfunctions lead to morphogenesis defects $[40,41]$. Furthermore, neurons or their processes that form incorrect connections are usually destroyed [42-45]. This process might explain the neurodegeneration observed in the medulla in the brain optic lobes in $s b r^{12} / D p(1 ; Y) y^{+} v^{+}$male larvae (Figure $\left.6 c, c^{\prime}\right)$. Establishment of the correct contacts between neurons and their targets is a necessary requirement for neuron survival $[27,42]$. The structural defects and neurodegeneration foci in the medulla of $s b r^{12} / D p(1 ; Y) y^{+} v^{+}$ adult males may also be consequences of the elimination of neurons that formed aberrant synaptic connections. It is important to note that the predominant location of the areas of neurodegeneration in the medulla was consistent with defects in the photoreceptor targeting in this neuropil. Since R-neurons assume the role of pioneer neurons in the formation of the medulla, the elimination of their axons can cause of the medulla malformations. There are many mechanisms of neurodegeneration, and defects in RNA-binding proteins have been proposed to be a cause of neurodegeneration [46-49]. The defects of axon pathfinding, photoreceptor axon bundle individualization, and neurodegeneration can occur due to malfunction of intercellular communications [12].

\subsection{The Non-Random Distribution of SBR in the Different Brain Cells}

The non-random distribution of SBR in the brain and in the eye-antennal imaginal disc (EAID) as a whole, and the characteristic subcellular localization of this protein, indicates the importance of SBR in the formation of certain structures during larval development. The SBR marks the optic stalk (Figure $7 \mathrm{a}^{\prime}, \mathrm{a}^{\prime \prime}, \mathrm{b}^{\prime}, \mathrm{b}^{\prime \prime}, \mathrm{c}$ ) and some neuroblasts with their daughter cells (Figure $7 b^{\prime}, b^{\prime \prime}$ ). The ommatidia boundaries are marked by anti-SBR in the eye-antennal imaginal disc that looks like a green mesh. All marked by SBR structures are involved in forming the medullar boundary facing the lamina. In the optic stalk, some glial cells and axons are enriched by $\operatorname{SBR}\left(7 \mathrm{a}^{\prime}, \mathrm{c}\right)$. The contacts of glial cells with neurons, including their axons, are required for glial cells migration [50]. Glial cell migration is regulated by the external signals causing changes in the cytoskeleton [51,52]. At the same time, glial cells themselves are the source of extracellular signals guiding the pathway of axons to their targets within the developing brain [53]. Axon pathfinding is exceptionally sensitive to the perturbation of the actin cytoskeleton [54,55]. The localization of SBR in the cytoplasm of glial cells and in the axons further supports the hypothesis that RNA-binding protein SBR is essential for cell-cell communications forming the boundaries between the brain compartments.

There are special markers that identify glial cells. A glia specific expression of the genes reversed polarity (repo) or glial cells missing $(\mathrm{gcm})$ allows to distinguish glial cells from neurons [12]. Nevertheless, there are some types of glial cells which can be recognized by the morphological criteria. On these criteria, it can be concluded that the SBR protein is enriched the nuclei and the cytoplasm of glial cells connected with the optic stalk (Figure $7 \mathrm{a}^{\prime}, \mathrm{a}^{\prime \prime}, \mathrm{b}^{\prime}, \mathrm{b}^{\prime \prime}, \mathrm{c}$ ). All photoreceptor axons come together in a thick bundle called an optic stalk, which connects the eye imaginal disc to the brain [56]. Various types of glial cells associate with the optic stalk $[57,58]$. The role of SBR in the functioning of specific types of glial cells is unknown.

Cytoplasmic localization of the SBR suggest the existence of the prospective RNAtargets in glial cells, as well as in neurons. This is particularly relevant for large specialized cells whose function is to rapidly respond to external signals. The wrapping glia is important for the spatial distribution of the axons of the photoreceptor neurons [59]. The glia is involved in the photoreceptor axonal projection [59]. In $s b r^{12} / D p(1 ; Y) y^{+} v^{+}$males, the defects of signaling between wrapping glia and axon bundles may result in the disordered axonal projections. Furthermore, the interaction between neurons and glia is essential for the establishment of sharp compartment boundaries in the brain [60,61]. 


\subsection{Allele-Specific Phenotypes of sbr Gene Mutations}

$s b r^{12} / D p(1 ; Y) y^{+} v^{+}$males are characterized by abnormalities in sexual behavior and lower activity in the test for negative geotaxis [19]. The sterile $s b r^{12}$ males do not have mobile spermatozoa [6]. Spermatozoa immobility is an allelespecific phenotype of $s b r^{12}$, $s b r^{17}$, and $s b r^{18}$ alleles. The male sterility of flies with mutant $s b r$ alleles is accompanied by axonemal abnormalities (i.e., defects in the cytoskeleton structure). The $s b r^{1}$ and $s b r^{2}$ alleles cause defects in bristle morphology, but homo- and hemizygotes animals are viable [62]. The bristles are a sensory organ of $D$. melanogaster whose development is a classic example of the realization of positional information during cell differentiation. As a rule, after asymmetric division, two daughter cells have unequal distributions of cytoplasmic determinants (including RNP complexes) and differ in their spindle apparatus orientation [63-66]. For example, segregation of neuroblasts from neuroepithelial cells and the subsequent asymmetric neuroblast divisions also depend on spindle orientation and non-random distribution of cytoplasmic determinants, which provide positional information.

NXF1 is a component of different macromolecular complexes, and it interacts with proteins and RNAs [67]. The specificities of these interactions are determined by the domain structure of an NXF1 (it contains a LRR (leucine-rich repeat) domain that controls protein-protein interactions, an NTF2L (nuclear transport 2 like) domain that supports an interaction with its partner protein NXT1, and an RBD (RNA-binding domain) and by conformational features of the entire molecule $[34,68]$.

Defects in one part of the NXF1 molecule may affect functions of some complexes without having significant effects on the functions of others. The propensity of NXF1 to multimerize imparts a wide range of variability in heterozygous individuals. RNP complexes can contain different ratios of normal to mutant protein subunits, and this variability can affect structural and functional features of the complex and explain variations in the dominant negative effects due to the presence of mutant subunits.

\section{Conclusions}

SBR protein is required for the formation of the inner structure and the establishment of boundaries in the medulla of the Drosophila visual system. Morphogenetic events and the establishment of brain compartment boundaries are influenced by the cytoskeleton and membrane-associated RNP-complexes. The disorganization of the brain compartment boundaries is also aggravated by the degeneration of neurons with abnormally terminated axons. The formation of brain compartment boundaries depends on intercellular communication with local translation participation. The distribution of SBR in the nucleus and cytoplasm of specific neurons and glial cells suggests specialized functions of this protein. Determining of the composition of cytoplasmic granules containing SBR and enriching specialized cells will undoubtedly contribute to the understanding of the functions of SBR in the cytoplasm.

Supplementary Materials: The following are available online at https:/ / www.mdpi.com/article/ 10.3390/cells10051144/s1, Figure S1: Axon terminals of the photoreceptors in the medulla of the optic lobe in adult males of different genotypes $\left(\mathrm{a}, \mathrm{a}^{\prime}-\right.$ Oregon- $\left.\mathrm{R}, \mathrm{b}, \mathrm{b}^{\prime}, \mathrm{c}, \mathrm{c}^{\prime}-s b r^{12} / D p(1 ; Y) y^{+} v^{+}\right)$. Cell nuclei were stained with DAPI $(\mathrm{a}-\mathrm{c})$. Autofluorescence allows to detect photoreceptor axon terminals $\left(a^{\prime}, c^{\prime}\right)$. Arrows indicate the R7-R8 axon terminals in the distal part of the medulla in Oregon-R $\left(a^{\prime}\right)$. In $s b r^{12} / D p(1 ; Y) y^{+} v^{+}$, autofluorescence $\left(\mathrm{b}^{\prime}, \mathrm{c}^{\prime}\right)$ is weaker, then in Oregon- $R$. The medulla structure is disrupted $\left(b, b^{\prime}\right)$. Axon terminals are not ordered and can be visualized by autofluorescence in the region marked on the top image (b) with higher magnification $\left(c^{\prime}\right)$. Scale bar: $a, a^{\prime}, b, b^{\prime}-50 \mu m$; $\mathrm{c}, \mathrm{c}^{\prime}-25 \mu \mathrm{m}$, Figure S2: Localization of the SBR protein in cells of the salivary glands of Drosophila. The SBR protein is mark nuclear envelop and cellular membrane. (a) DAPI (DNA stain); (b) phalloidin (F-actin stain); (c) anti-SBR; (d) merge. Scale bar: $50 \mu \mathrm{m}$.

Author Contributions: Conceptualization, E.G. and L.M.; methodology, E.G., D.K., and A.Y.; validation, E.G. and A.Y.; formal analysis, A.Y.; investigation, A.Y. and E.G.; resources, D.K.; writingoriginal draft preparation, E.G. and L.M.; writing-review and editing, A.Y. and D.K.; visualization, 
A.Y. and E.G.; supervision, L.M.; funding acquisition, L.M. All authors have read and agreed to the published version of the manuscript.

Funding: This research was funded by the Russian Foundation for Basic Research, 19-0401255.

Institutional Review Board Statement: Not applicable.

Informed Consent Statement: Not applicable.

Acknowledgments: We are grateful to the staff of the Chromas Core Facility (the Center of study of ultrastructure and molecular composition of biological objects at Biological Faculty of St. Petersburg State University).

Conflicts of Interest: The authors declare no conflict of interest. The funders had no role in the design of the study; in the collection, analyses, or interpretation of data; in the writing of the manuscript, or in the decision to publish the results.

\section{Appendix A}

Recombination mapping of lethal mutations for confirm the single mutation presence on the $\mathrm{x}$ chromosome in $s b r^{12} / D p(1 ; Y) y^{+} v^{+}$males.

\section{References}

1. Herold, A.; Klymenko, T.; Izaurralde, E. NXF1/p15 heterodimers are essential for mRNA nuclear export in Drosophila. RNA 2001, 7, 1768-1780. [CrossRef]

2. Tretyakova, I.V.; Lyozin, G.T.; Markova, E.G.; Evgen'ev, M.B.; Mamon, L.A. The sbr gene product in Drosophila melanogaster and its orthologs in yeast (Mex67p) and human (TAP). Russ. J. Genet. 2001, 37, 593-602. [CrossRef]

3. Wilkie, G.S.; Zimyanin, V.; Kirby, R.; Korey, C.; Francis-Lang, H.; Van Vactor, D.; Davis, I. Small bristles, the Drosophila ortholog of NXF-1, is essential for mRNA export throughout development. RNA 2001, 7, 1781-1792. [CrossRef]

4. Bachi, A.; Braun, I.C.; Rodrigues, J.P.; Panté, N.; Ribbeck, K.; von Kobbe, C.; Kutay, U.; Wilm, M.; Görlich, D.; CarmoFonseca, M.; et al. The C-terminal domain of TAP interacts with the nuclear pore complex and promotes export of specific CTE-bearing RNA substrates. RNA 2000, 6, 136-158. [CrossRef] [PubMed]

5. Atsapkina, A.A.; Golubkova, E.V.; Kasatkina, V.V.; Avanesyan, E.O.; Ivankova, N.A.; Mamon, L.A. Peculiarities of spermatogenesis in Drosophila melanogaster: Role of main transport receptor of mRNA (Dm NXF1). Cell Tissue Biol. 2010, 4, 429-435. [CrossRef]

6. Golubkova, E.V.; Atsapkina, A.A.; Mamon, L.A. The role of sbr/ Dm nxf1 gene in syncytial development in Drosophila melanogaster. Cell Tissue Biol. 2015, 9, 271-283. [CrossRef]

7. Yakimova, A.O.; Pugacheva, O.M.; Golubkova, E.V.; Mamon, L.A. Cytoplasmic localization of SBR (Dm NXF1) protein and its zonal distribution in the ganglia of Drosophila melanogaster larvae. Invertebr. Neurosci. 2016, 16, 9. [CrossRef]

8. Mamon, L.A.; Ginanova, V.R.; Kliver, S.F.; Yakimova, A.O.; Atsapkina, A.A.; Golubkova, E.V. RNA-binding proteins of the NXF (nuclear export factor) family and their connection with the cytoskeleton. Cytoskeleton 2017, 74, 161-169. [CrossRef]

9. Holt, C.E.; Schuman, E.M. The central dogma decentralized: New perspectives on RNA function and local translation in neurons. Neuron 2013, 80, 648-657. [CrossRef]

10. Chotard, C.; Salecker, I. Glial cell development and function in the Drosophila visual system. Neuron Glia Biol. 2007, 3, 17-25. [CrossRef]

11. Spindler, S.R.; Ortiz, I.; Fung, S.; Takashima, S.; Hartenstein, V. Drosophila cortex and neuropile glia influence secondary axon tract growth, pathfinding. And fasciculation in the developing larval brain. Dev. Biol. 2009, 334, 355-368. [CrossRef]

12. Edwards, T.N.; Meinertzhagen, I.A. The functional organization of glia in the adult brain of Drosophila and other insects. Prog. Neurobiol. 2010, 90, 471-497. [CrossRef] [PubMed]

13. Meinertzhagen, I.A.; Hanson, T.E. The development of the optic lobe. In The Development of Drosophila Melanogaster; Bate, M., MartinezArias, A., Eds.; Cold Spring Harbor Laboratory Press: New York, NY, USA, 1993; pp. 1363-1491.

14. Braitenberg, V. Patterns of projection in the visual system of the fly. I. Retina-lamina projections. Exp. Brain Res. 1967, 3, 271-298. [CrossRef] [PubMed]

15. Trujilo-Cenóz, O.; Melamed, J. Compound eye of dipterans: Anatomical basis for integration-An electron microscope study. J. Ultrastruct Res. 1966, 16, 395-398. [CrossRef]

16. Meinertzhagen, I.A.; Sorra, K.E. Synaptic organization in the fly's optic lamina: Few cells, many synapses and divergent microcircuits. Prog. Brain Res. 2001, 131, 53-69. [CrossRef]

17. Fischbach, K.F.; Hiesinger, P.R. Optic lobe development. Adv. Exp. Med. Biol. 2008, 628, 115-136. [CrossRef] [PubMed]

18. Gontang, A.C.; Hwal, J.J.; Mast, J.D.; Schwabe, T.; Clandinin, T.R. The cytoskeletal regulator Genghis khan is required for columnar target specificity in the Drosophila visual system. Development 2011, 138, 4899-4909. [CrossRef] [PubMed]

19. Yakimova, A.O.; Golubkova, E.V.; Sarantseva, S.V.; Mamon, L.A. Ellipsoid body and medulla defects and locomotion disturbances in sbr (small bristles) mutants of Drosophila melanogaster. Russ. J. Genet. 2018, 54, 609-617. [CrossRef] 
20. Kuroda, M.I.; Hilfiker, A.; Lucchesi, J.C. Dosage compensation in Drosophila-A model for the coordinate regulation of transcription. Genetics 2016, 204, 435-450. [CrossRef]

21. Martín-Peña, A.; Acebes, A.; Rodríguez, J.-R.; Chevalier, V.; Casas-Tinto, S.; Triphan, T.; Strauss, R.; Ferrúset, A. Cell types and coincident synapses in the ellipsoid body of Drosophila. Eur. J. Neurosci. 2014, 39, 1586-1601. [CrossRef]

22. Jan, L.Y.; Jan, Y.N. Antibodies to horseradish peroxidase as specific neuronal markers in Drosophila and in grasshopper embryos. Proc. Natl. Acad. Sci. USA 1982, 79, 2700-2704. [CrossRef] [PubMed]

23. Kopytova, D.; Popova, V.; Kurshakova, M.; Shidlovskii, Y.; Nabirochkina, E.; Brechalov, A.; Georgiev, G.; Georgieva, S. ORC interacts with THSC/TREX-2 and its subunits promote Nxf1 association with mRNP and mRNA export in Drosophila. Nucl. Acid Res. 2016, 44, 4920-4933. [CrossRef] [PubMed]

24. Kiszely, D. Practical Microtechniques and Histochemistry; Hungarian Academy of Sciences Publishing House: Budapest, Hungary, 1962; p. 382. (In Russian)

25. Fischbach, K.F.; Dittrich, A.P.M. The optic lobe of Drosophila melanogaster. I. A Golgi analysis of wild type structure. Cell Tissue Res. 1989, 258, 441-475. [CrossRef]

26. Apitz, H.; Salecker, I. A Challenge of Numbers and Diversity: Neurogenesis in the Drosophila Optic Lobe. J. Neurogenet. 2014, 28, 233-249. [CrossRef] [PubMed]

27. Yamaguchi, Y.; Miura, M. Programmed cell death in neurodevelopment. Dev. Cell 2015, 32, 478-490. [CrossRef]

28. Poeck, B.; Fischer, S.; Gunning, D.; Zipursky, S.L.; Salecker, I. Glial Cells Mediate Target Layer Selection of Retinal Axons in the Developing Visual System of Drosophila. Neuron 2001, 29, 99-113. [CrossRef]

29. Herold, A.; Teixeira, L.; Izaurralde, E. Genome-wide analysis of nuclear mRNA export pathways in Drosophila. EMBO J. 2003, 22, 2472-2483. [CrossRef]

30. Ginanova, V.; Golubkova, E.; Kliver, S.; Bychkova, E.; Markoska, K.; Ivankova, N.; Tretyakova, I.; Evgen'ev, M. Testis-specific products of the Drosophila melanogaster sbr gene, encoding nuclear export factor 1, are necessary for male fertility. Gene 2016, 577, 153-160. [CrossRef] [PubMed]

31. Fribourg, S.; Braun, I.C.; Izaurralde, E.; Conti, E. Structural basis for the recognition of a nucleoporin FG repeat by the NTF2-like domain of the TAP/p15 mRNA nuclear export factor. Mol. Cell 2001, 8, 645-656. [CrossRef]

32. Braun, I.C.; Herold, A.; Rode, M.; Izaurralde, E. Nuclear export of mRNA by TAP/NXF1 requires two nucleoporin-binding sites but not p15. Mol. Cell Biol. 2002, 22, 5405-5418. [CrossRef]

33. Aibara, S.; Katahira, J.; Valkov, E.; Stewart, M. The principal mRNA nuclear export factor NXF1:NXT1 forms a symmetric binding platform that facilitates export of retroviral CTE-RNA. Nucleic Acids Res. 2015, 43, 1883-1893. [CrossRef] [PubMed]

34. Katahira, J.; Dimitrova, L.; Imai, Y.; Hurt, E. NTF2-like domain of Tap plays a critical role in cargo mRNA recognition and export. Nucleic Acids Res. 2015, 43, 1894-1904. [CrossRef] [PubMed]

35. Ivankova, N.; Tretyakova, I.; Lyozin, G.; Avanesyan, E.; Zolotukhin, A.; Zatsepina, O.G.; Evgen'ev, M.B.; Mamon, L.A. Alternative transcripts expressed by small bristles, the Drosophila melanogaster nxf1 gene. Gene 2010, 458, 11-19. [CrossRef]

36. Cammarata, G.M.; Bearce, E.; Lowery, L.A. Cytoskeletal social networking in the growth cone: +TIPs mediate microtubule-actin cross-linking to drive axon outgrowth and guidance. Cytoskeleton 2016, 73, 461-476. [CrossRef]

37. Zhang, B.; Herman, P.K. It is all about the process(ing): P-body granules and the regulation of signal transduction. Curr. Genet. 2020, 66, 73-77. [CrossRef] [PubMed]

38. Yoon, D.W.; Lee, H.; Seol, W.; DeMaria, M.; Rosenzweig, M.; Jung, J.U. Tap: A novel protein that interacts with tip of herpesvirus saimiri and induces lymphocyte aggregation. Immunity 1997, 6, 571-582. [CrossRef]

39. Herold, A.; Suyama, M.; Rodrigues, J.P.; Braun, I.C.; Kutay, U.; Carmo-Fonseca, M.; Bork, P.; Izaurralde, E. TAP (NXF1) belongs to a multigene family of putative RNA export factors with a conserved modular architecture. Mol. Cell Biol. 2000, 20, 8996-9008. [CrossRef]

40. Kurusu, M.; Katsuki, T.; Zinn, K.; Suzuki, E. Developmental changes in expression, subcellular distribution, and function of Drosophila N-cadherin, guided by a cell-intrinsic program during neuronal differentiation. Dev. Biol. 2012, 366, 204-217. [CrossRef]

41. Missaire, M.; Hindges, R. The role of cell adhesion molecules in visual circuit formation: From neurite outgrowth to maps and synaptic specificity. Dev. Neurobiol 2015, 75, 569-583. [CrossRef] [PubMed]

42. Buss, R.R.; Sun, W.; Oppenheim, R.W. Adaptive roles of programmed cell death during nervous system development. Annu. Rev. Neurosci. 2006, 29, 1-35. [CrossRef]

43. Rogulja-Ortmann, A.; Luer, K.; Seibert, J.; Rickert, C.; Technau, G.M. Programmed cell death in the embryonic central nervous system of Drosophila melanogaster. Development 2007, 134, 105-116. [CrossRef]

44. Jiang, Y.; Reichert, H. Programmed cell death in type II neuroblast lineages is required for central complex development in the Drosophila brain. Neural Dev. 2012, 7, 3. [CrossRef] [PubMed]

45. Baek, M.; Enriquez, J.; Mann, R.S. Dual role for Hox genes and Hox co-factors in conferring leg motoneuron survival and identity in Drosophila. Development 2013, 140, 2027-2038. [CrossRef] [PubMed]

46. Sephton, C.F.; Yu, G. The function of RNA-binding proteins at the synapse: Implications for neurodegeneration. Cell Mol. Life Sci. 2015, 72, 3621-3635. [CrossRef] [PubMed]

47. De Conti, L.; Baralle, M.; Buratti, E. Neurodegeneration and RNA-binding proteins. WIREs RNA 2017, 8, e1394. [CrossRef] [PubMed] 
48. Conlon, E.G.; Manley, J.L. RNA-binding proteins in neurodegeneration: Mechanisms in aggregate. Gene Dev. 2017, 31, 1509-1528. [CrossRef]

49. Ito, D.; Hatano, M.; Suzuki, N. RNA binding proteins and the pathological cascade in ALS/FTD neurodegeneration. Sci. Transl. Med. 2017, 9, eaah5436. [CrossRef] [PubMed]

50. Cafferty, P. Carpet cells regulate glial cell motility in the developing Drosophila eye. J. Neurosci. 2008, 28, 2686-2687. [CrossRef]

51. Cafferty, P.; Xie, X.; Browne, K.; Auld, V.J. Live imaging of glial cell migration in the eye imaginal disc. J. Vis. Exp. 2009, 29, 1155. [CrossRef] [PubMed]

52. Myers, J.P.; Santiago-Medina, M.; Gomez, T.M. Regulation of axonal outgrowth and pathfinding by integrin-ECM interactions. Dev. Neurobiol. 2011, 71, 901-923. [CrossRef]

53. Fernandes, V.M.; Chen, Z.; Rossi, A.M.; Zipfel, J.; Desplan, C. Glia relay differentiation cues to coordinate neuronal development in Drosophila. Science 2017, 357, 886-891. [CrossRef] [PubMed]

54. Luo, L. Actin cytoskeleton regulation in neuronal morphogenesis and structural plasticity. Annu. Rev. Cell Dev. Biol. 2002, 18, 601-635. [CrossRef]

55. Dent, E.W.; Merriam, E.B.; Hu, X. The dynamic cytoskeleton: Backbone of dendritic spine plasticity. Curr. Opin. Neurobiol. 2011, 21, 175-181. [CrossRef]

56. Reddy, B.V.V.G.; Irvine, K.D. Regulation of Drosophila glial cell proliferation by Merlin-Hippo signaling. Development 2011, 138, 5201-5212. [CrossRef]

57. Silies, M.; Yuva, Y.; Engelen, D.; Aho, A.; Stork, T.; Klämbt, C. Glial cell migration in the eye disc. J. Neurosci. 2007, 27, 13130-13139. [CrossRef] [PubMed]

58. Xie, X.; Gilbert, M.; Petley-Ragan, L.; Auld, V.J. Loss of focal adhesions in glia disrupts both glial and photoreceptor axon migration in the Drosophila visual system. Development 2014, 141, 3072-3083. [CrossRef]

59. Chang, Y.-C.; Tsao, C.-K.; Sun, H. Temporal and spatial order of photoreceptor and glia protections into optic lobe in Drosophila. Sci. Rep. 2018, 8, 12669. [CrossRef] [PubMed]

60. Tayler, T.D.; Robichaux, M.B.; Garrity, P.A. Compartmentalization of visual centers in the Drosophila brain requires Slit and Robo proteins. Development 2004, 131, 5935-5945. [CrossRef]

61. Suzuki, T.; Liu, C.; Kato, S.; Nishimura, K.; Takechi, H.; Yasugi, T.; Takayama, R.; Hakeda-Suzuki, S.; Suzuki, T.; Sato, M. Netrin signaling defines the regional border. Science 2018, 8, 148-160. [CrossRef]

62. Available online: https:/ / flybase.org/reports/FBgn0003321 (accessed on 18 April 2021).

63. Knoblich, J.A. Mechanisms of asymmetric cell division during animal development. Curr. Opin. Cell Biol. 1997, 9, 833-841. [CrossRef]

64. Roegiers, F.; Jan, Y.N. Asymmetric cell division. Curr. Opin. Cell Biol. 2004, 16, 195205. [CrossRef] [PubMed]

65. Egger, B.; Chell, J.M.; Brand, A.H. Insights into neural stem cell biology from flies. Philos. Trans. R. Soc. Lond. B Biol. Sci. 2008, 363, 39-56. [CrossRef]

66. Neumüller, R.A.; Knoblich, J.A. Dividing cellular asymmetry: Asymmetric cell division and its implications for stem cells and cancer. Genes Dev. 2009, 23, 2675-2699. [CrossRef] [PubMed]

67. Viphakone, N.; Hautbergue, G.M.; Walsh, M.; Chang, C.T.; Holland, A.; Folco, E.G.; Reed, R.; Wilson, S.A. TREX exposes the RNA-binding domain of Nxf1 to enable mRNA export. Nat. Commun. 2012, 3, 1006. [CrossRef] [PubMed]

68. Valkov, E.; Dean, J.C.; Jani, D.; Kuhlmann, S.I.; Stewart, M. Structural basis for the assembly and disassembly of mRNA nuclear export complexes. Biochim. Biophys. Acta 2012, 181, 578-592. [CrossRef] [PubMed] 